\title{
ВОСТРЕБОВАННОСТЬ ВЫСШЕГО ОБРАЗОВАНИЯ В ФЕДЕРАЛЬНЫХ УНИВЕРСИТЕТАХ В ИНФОРМАЦИОННОЙ СРЕДЕ
}

\author{
(C) 2021 Колесникова Юлия Сергеевна \\ доктор экономических наук, \\ профессор Департамента психологии и развития человеческого капитала \\ Финансовый университет при Правительстве Российской Федерации, Россия, Москва \\ E-mail:hulia_k@mail.ru \\ (c) 2021 Бычков Глеб Александрович \\ ведущий аналитик данных ГК Innostage \\ E-mail: bychkov.gleb@gmail.com \\ () 2021 Шафигуллин Искандер Ильдарович \\ Руководитель проектов McKinsey \& Company \\ E-mail: isk.shafigullin@gmail.com
}

Востребованность высшего образования, востребованность вуза определяется многими факторами, в частности узнаваемостью бренда вуза в сети Интернет. В условиях цифровизации бренд университета формируется во многом в информационной среде и воздействует на выбор абитуриента. Целью данного исследования является операционный анализ потребности образования в федеральных университетах через анализ динамики запросов востребованности в информационной среде.

Ключевые слова: потребность в образовании, информационная среда, бренд федерального вуза, оперативный анализ, цифровизация, поисковый запрос.

Федеральные вузы возникают, начиная с 2012 г. в результате реформирования системы высшего образования. Происходит сокращение количества высших учебных заведений и их объединение в рамках федеральных вузов. Целью данных преобразований являлось сокращение неэффективных высших учебных заведений. Она предполагала сокращение числа вузов на $40 \%$, а филиалов - на $80 \%[1]$.

В условиях цифровизации бренд университета формируется во многом в информационной среде и воздействует на выбор абитуриента. Целью данного исследования являлась оценка востребованности федеральных университетов в информационной среде. В данном случае было сделано допущение, что запросы пользователей коррелируют с их положительным мнением о вузе. Для чего были проанализированы запросы в Yandex по наименованиям и аббревиатурам федеральных вузов. При этом необходимо отметить, что число студентов в федеральных вузах, их позиции в рейтингах, число преподавателей сильно дифференцированы. Численность студентов представлена на рисунке 1.

Наибольшее число студентов наблюдается в Казанском (Приволжском) федеральном университете, что коррелирует с высокими позициями в рейтингах Times Higher Education: World University Rankings, и QS World University Ranking. Наименьший показатель по количеству студентов у Балтийского федерального университета.

Вопросами исследования оценки брендов занимались М.Портер[3], D. Aaker[4], Becсасесе F[5], Boos M[6], Smith G., Parr R.[7].

Среди российских авторов, исследующих оценку бренда следует выделить Гвоздецкую И.В.[8], Васильева И.В., Васильева Т.Н., Мухопад В. И.[9] Важенина И. С.,[10], КозейчукД.А. [11] и др. Бренд федеральных университетов исследовался в меньшей степени, среди авторов изучающих данную тему необходимо выделить работы ШевченкоД.А.[12], Родькина П.Е.[13], Зинчук Г. М., Карнаух И. С.[14] и др.

Однако в эпоху быстрого развития информационных технологий и появления образовательных онлайн платформ конкурентное давление на классические университеты обострилось еще сильнее во время пандемии COVID-19, когда университетам пришлось перейти на дистанционное образование, потеряв тем самым 


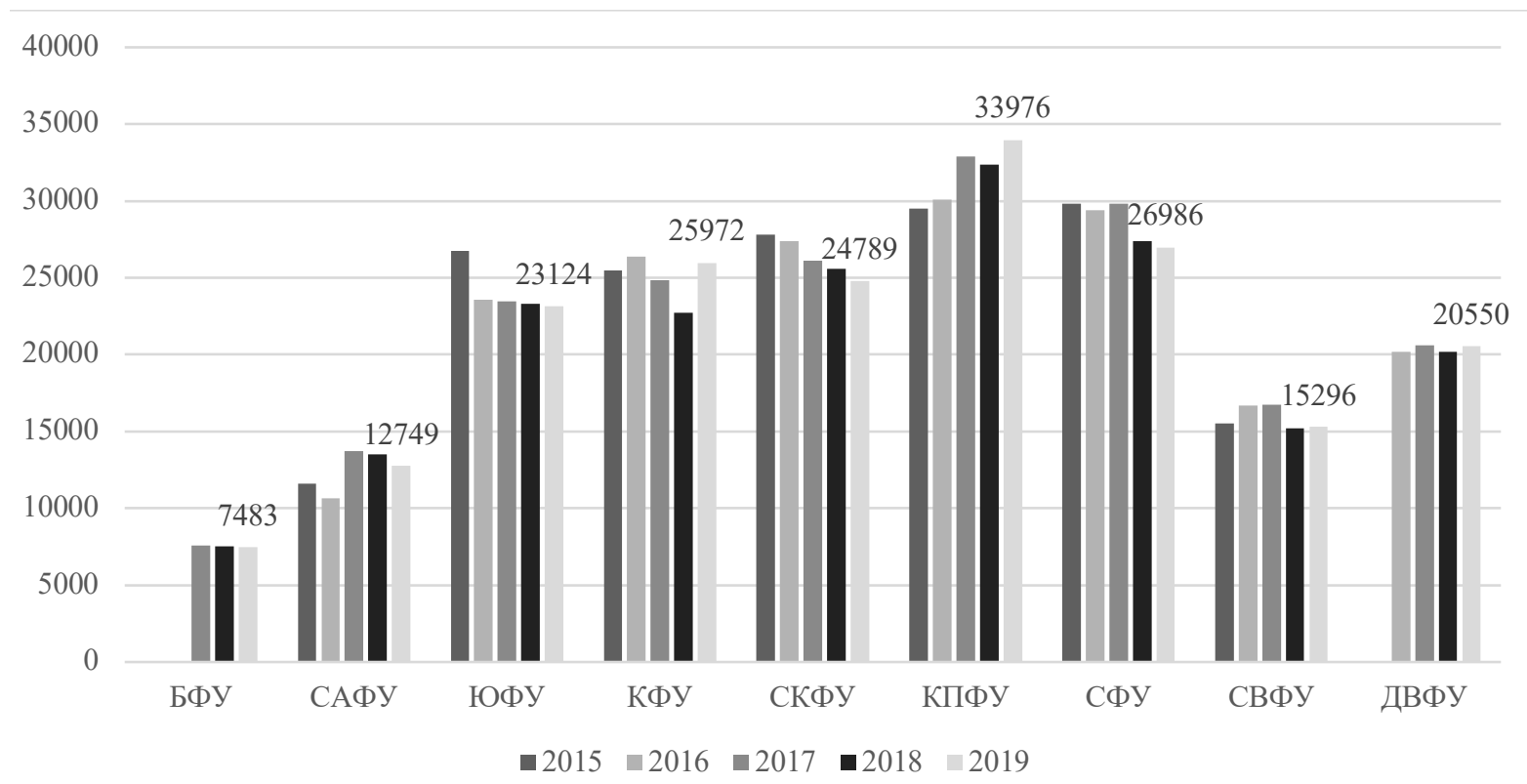

Pис. 1. Численность студентов в федеральных университетах (чел.) [2]

свое конкурентное преимущество перед онлайн платформами.

Исследование сфокусировано на внешнем бренде федеральных вузов, который зависит от коммуникативных характеристик и идентификаторов учреждения. Исходными данными для анализа являются такие инструменты как wordstat.yandex.ru, SEM rush, Yandex. Meтодологией анализа являются статистические и экономико-математические методы. Исследована география поступления запросов по регионам РФ и странам. Информационной базой выступали запросы пользователей интернет о федеральных вузах. Существует множество подходов к оценке брендов: метод суммарных издержек, рыночная оценка, метод стоимости расширения и др. В том числе присутствует метод оценки через анализ мнений потребителей.

Выбор вуза осуществляется абитуриентами в зависимости от тех факторов, которые являются приоритетными для их решения. В условиях цифровизации бренд университета формируется во многом в информационной среде и воздействует на выбор абитуриента.

В условиях высокой конкуренции как между вузами, так и в образовательной среде в целом, стратегические решения федеральных университетов необходимо основывать как на качественных, так и количественных показателях. Основным динамическим периодом показателей университета является один год, в понятие динамический период закладывается период, в который происходит максимальное вариационное временное изменение показателей. Так, в течение одного года такой показатель, как количество студентов, не будет сильно изменяться, хотя существуют такие события, как отчисление студентов до получения диплома, переводы между вузами и другие, которые изменяют показатель, однако значительное изменение количества студентов в высшем учебном заведении происходит во время отчисления студентов по получении квалификации и во время приемной кампании университета. Финансовое и стратегическое планирование в университетах может иметь еще более длительный период. Таким образом, если параметры распределения не зависят от времени, так, если использовать допущение того, что показатель имеет нормальное распределение, то его среднее и дисперсия не изменяются во времени. В годовых данных условие стационарности часто нарушается, что делает невозможным использование прогнозирования на основе метода временных рядов. Для преодоления проблемы отсутствия операционных данных и преобразования нестационарных рядов предлагается использование параметра «интерес к университету». Показатель интереса определяется, как количественный показатель репутационного капитала вуза.

Каждый студент проходит цепочку: интерес $=>$ подача заявления => одобрение универ- 
ситетом $=>$ получение услуги. По данной схеме интерес - это стартовая точка появления пары студент - университет. Более высокий показатель интереса к университету дает возможность последнему возможность отбора студента с более высоким средним балом поступления, а также существует прямая теоретическая зависимость между интересом к университету и его узнаваемостью, нематериальным параметром, который также является одним из ключевых индикаторов, которые учитывают академические рейтинги. Таким образом, интерес к университету является количественным параметром репутационного капитала, который является нереализованной потребностью в получении образовательной услуги.

Для количественной оценки нематериального параметра «интерес к университету» будут использоваться исторические данные запросов пользователей сети интернет названий университетов. Рынок поисковых систем в России является классическим примером олигопольного рынка, две основных поисковых систем, которые конкурируют между собой - это Google (Гугл) и Yandex (Яндекс), также на территории Российской Федерации существуют поисковые системы Mail.ru, Bind, и другие системы. Доля среднесуточный запросов в поисковой системе Гугл в России составляет в 2021 году 63,1\%, доля Яндекса 35,5\%, доля остальных систем составляет $1,4 \%$. Системы учета в Яндексе предоставляет абсолютное и относительное количество запросов по заданной тематике. Данные Google Trends не отражают абсолютный уровень запросов для данного поискового запроса. Скорее, он сообщает индекс запроса, или как называет его сам Гугл, интерес.

Одним из преимуществ использования поисковой системы Яндекс является то, что система предоставляет исторические данные абсолютного количества запросов, используя это преимущество можно сложить все запросы всех федеральных высших учебных заведений и получить общероссийскую динамику (рисунок 2).

Рисунок 2 отображает динамику количества запросов федеральных вузов в поисковой системе Yandex. Интересным наблюдением данного графика является то, что аббревиатура университета используется в качестве запроса в среднем в 24 раза чаще, чем использование полного названия университета.

Мы считаем, что аббревиатура университета является более сильным брендом, чем его полное название в информационных экономических системах. Ориентация и продвижение аббревиатуры университета в информационных системах (в социальных сетях, интернете и других информационных сетях) позволит формировать и аккумулировать нематериальный капитал бренда не только во время приемных кампаний, но и во время обучающего процесса.

Максимальное количество запросов полного названий федеральных университетов составило 116903 запросов, в то время как максимальное количество запросов аббревиатур составило 2319719 запросов, оба пика пришлись на август 2020 года, время приемной кампании 2020 года. График имеет явную сезонность с повышенны-

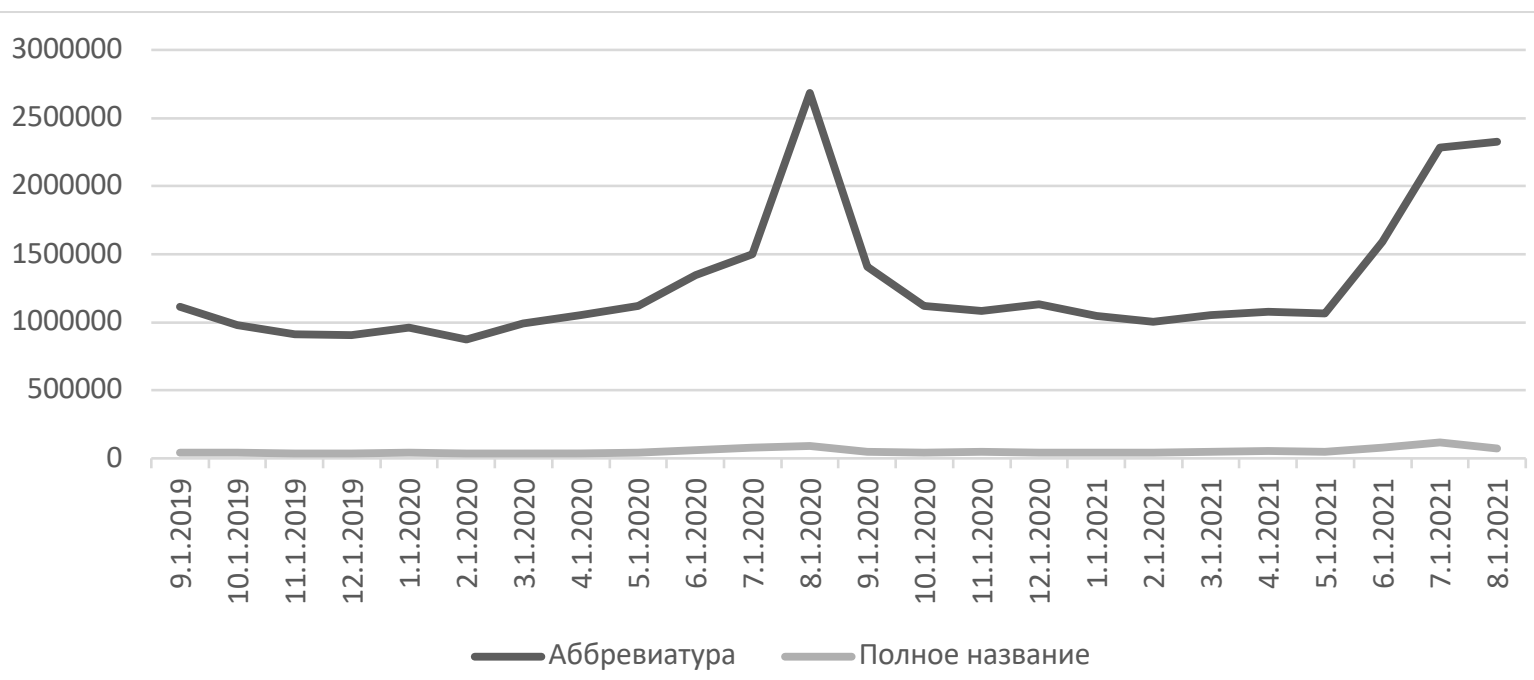

Puc. 2. Динамика интереса к федеральным вузам, Yandex 
ми значениями в июле-августе. Среднее количество запросов полных названий составляет 52748 запросов, аббревиатур - 1275106.

Наибольшее среднемесячное количество поисковых запросов в системе Yandex в период с сентября 2019 года по август 2021 года наблюдалось в Казанском федеральном университете (таблица 1) и составляло 309252 запроса в месяц, вторым по величине запросов стал Уральский федеральный университет, количество запросов «УрФУ» составило 234737 запросов. Третье место занимает Сибирский федеральный университет со среднемесячным количеством запросов 177853.

Коэффициент корреляции Пирсона в логарифмической шкале $-0,74$, что говорит о высокой корреляции между параметрами количества запросов и количества студентов федеральных вузов. Наибольшее количество запросов приходится на регион, в котором расположен федеральный университет. Доля региона с наибольшим количеством запросов в топ-5 регионов для всех вузов составляет более $80 \%$, что говорит нам о том, что географическое покрытие поиска федеральных вузов сильно сконцентрировано около или в самом регионе, в котором расположен университет.

Заключение. В ходе исследования были проанализированы запросы в Yandex по наиме- нованиям и аббревиатурам федеральных вузов статистическими методами. Исходными данными для анализа являются такие инструменты как wordstat.yandex.ru, SEM rush, Yandex. Число поисковых запросов в отношении федерального вуза коррелирует с численностью студентов, что позволяет использовать запросы как прогнозный инструмент. Наибольшее количество запросов приходится на регион, в котором расположен федеральный университет, что говорит о региональности федерального вуза. Для преодоления проблемы отсутствия операционных данных и преобразования нестационарных рядов предлагается использование параметра «интерес к университету». Показатель «интерес» определяется как количественный показатель востребованности федерального вуза.

Наиболее частыми регионами поиска федерального университета являются города федерального значения - Москва и Санкт-Петербург, города в которых проживает наибольшее количество людей в Российской Федерации, это говорит нам о том, что адекватным параметром интереса к университетам должен быть относительный индекс количества запросов (абсолютное количество/население в регионе). Однако даже нормализация не опровергнет того факта, что запросы сконцентрированы в регионе расположения федерального вуза. Наимень-

Таблица 1. Показатели поисковых запросов по федеральным вузам, Yandex

\begin{tabular}{|c|c|c|c|c|}
\hline Университет & $\begin{array}{c}\text { Соотношение по- } \\
\text { иска аббревиатуры } \\
\text { университета к пол- } \\
\text { ному названию }\end{array}$ & $\begin{array}{c}\text { Минимальное } \\
\text { количество запро- } \\
\text { сов аббревиатуры } \\
\text { университета }\end{array}$ & $\begin{array}{c}\text { Среднее количество } \\
\text { запросов аббревиа- } \\
\text { туры университета }\end{array}$ & $\begin{array}{c}\text { Максимальное } \\
\text { количество запро- } \\
\text { сов аббревиатуры } \\
\text { университета }\end{array}$ \\
\hline БФУ & 15.98 & $\begin{array}{c}25265 \\
(2019-12)\end{array}$ & 43450 & $\begin{array}{c}116289 \\
(2020-08)\end{array}$ \\
\hline ДВФУ & 19.82 & $\begin{array}{c}71114 \\
(2020-02)\end{array}$ & 106733 & $\begin{array}{c}202541 \\
(2020-08)\end{array}$ \\
\hline КФУ & 25.08 & $\begin{array}{c}203797 \\
(2020-02)\end{array}$ & 309252 & $\begin{array}{c}749864 \\
(2020-08)\end{array}$ \\
\hline САФУ & 74.84 & $\begin{array}{c}106807 \\
(2020-07)\end{array}$ & 131180 & $\begin{array}{c}171450 \\
(2020-08)\end{array}$ \\
\hline СВФУ & 25.66 & $\begin{array}{c}22713 \\
(2020-01)\end{array}$ & 38250 & $\begin{array}{c}60507 \\
(2020-08)\end{array}$ \\
\hline СКФУ & 16.42 & $\begin{array}{c}48649 \\
(2020-04)\end{array}$ & 76310 & $\begin{array}{c}174672 \\
(2020-08)\end{array}$ \\
\hline СФУ & 24.70 & $\begin{array}{c}117589 \\
(2019-12)\end{array}$ & 177853 & $\begin{array}{c}350388 \\
(2020-08)\end{array}$ \\
\hline УрФУ & 28.71 & $\begin{array}{c}147981 \\
(2019-12)\end{array}$ & 234737 & $\begin{array}{c}500701 \\
(2020-08)\end{array}$ \\
\hline ЮФУ & 17.38 & $\begin{array}{c}92801 \\
(2019-11)\end{array}$ & 157337 & $\begin{array}{c}364158 \\
(2020-08)\end{array}$ \\
\hline
\end{tabular}


шее среднее количество запросов наблюдается в Северо-Восточном федеральном университете, которое составляет 38250 запросов, далее идет Балтийский федеральный университет (43450 запросов), тройку университетов с наименьшим количеством запросов закрывает СевероКавказский федеральный университет (76310 запросов). Таким образом, поисковая система
Yandex предоставляет нам показатель абсолютного количества запросов федеральных вузах. Коэффициент корреляции количества студентов и среднегодового количества запросов составляет больше 0,7 , что позволяет прогнозировать число поступающих. Запросы сильно сконцентрированы в регионе, где располагается федеральный университет.

\section{Библиографический список}

1. Лазар М.Г. Реформа высшего образования России - итоги и последствия глазами социологии образования / Социальные и гуманитарные науки. - 2018 - С. 95-108.

2. Составлено авторами на основе отчетов о самообследовании федеральных вузов.

3. Портер М. Международная конкуренция. - М, Прогресс, 1993. - 896 с.

4. Aaker D. Managing Brand Equity // Free Press. 1991. P. 13-15.

5. Beccacece F. Risk Analysis in Brand Valuation // Bocconi University, Italy.2006. P. 32.

6. Boos M. International Transfer Pricing: The Valuation of Intangible Assets // Kluwer Law International Journal. 2003. Vol. 3. P. 2435.

7. Smith G., Parr R. Valuation of Intellectual Property and Intangible Assets // John Wiley\&Sons.1983. Vol.3. P. 512.

8. Гвоздецкая И. В. Методы оценки стоимости брендов/ Маркетинг. 2009. № 1 (104). С. 61-74.

9. Васильева И.В., Васильева Т. Н., Мухопад В. И. Оценка стоимости бренда: проблемы и методики (зарубежный и отечественный опыт) монография, 2008.С.71-73.

10. Важенина И.С., Важенин С.Г. Имидж и репутация как стратегические составляющие нематериальных активов территории//Экономика региона. 2010. № 3 (23). С. 95-103.

11. Багиев Г.Л., КозейчукД. А. Оценка стоимости бренда в контексте лояльности потребителей//Бренд-менеджмент. 2006. № 3. С. 146-154.

12. Шевченко Д.А. Маркетинг в сфере образования. Статья 3. Брендинг и ребрендинг вузов на современном рынке образования// Практический маркетинг. 2017. № 4 (242). С. 3-11.

13. Родькин П.Е. Брендинг территорий: облако ассоциаций территории как исследовательская и проектная часть дисциплины на примере магистерской программы НИУ ВШЭ// Знание. Понимание. Умение. 2017. № 2. C. $249-257$.

14. Зинчук Г.М., Карнаух И. С. Роль опорных университетов в экономическом развитии регионов//Экономика и предпринимательство. 2020. № 10 (123). С. 310-313.

15. Сафиуллин М.Р., Ельшин Л.А., Фахрутдинова Е.В. Эффективность развития региональной высшей школы: качественно-количественный анализ (на примере Приволжского федерального округа)// Alma mater (Becтник высшей школы). 2019. № 12. С. 55-61. 